\title{
LAS RAÍCES HISTÓRICAS DEL ATRASO ECONÓMICO EN ÁFRICA SUBSAHARIANA*
}

\author{
Lito Nunes Fernandes'
}

\begin{abstract}
Resumen
En la actualidad, los estudios sobre el desarrollo económico y reducción de la pobreza de los países en desarrollo y sobretodo de África Subsahariana levantan la atención de especialistas de todo el mundo y sus investigaciones son realizadas desde perspectivas teóricas muy diversas. A pesar de múltiplos esfuerzos hechos, todavía no se ha encontrado un plan de desarrollo integrado en África Subsahariana, una vez que las ideologías políticas reinantes, no consiguen despegar de los procesos de producción delineados en el ámbito del modelo de producción colonial. Para entender la situación de África Subsahariana, irremediablemente hay que vincular su proceso de desarrollo con sus ex metrópolis. En esta dirección el objetivo de este artículo consiste en presentar el origen y las causas de subdesarrollo así como las principales iniciativas hechas en la tentativa de salir del marasmo en una coyuntura económica globalizada totalmente desfavorable para los países de la región en cuestión.
\end{abstract}

Palabras Clave: África Subsahariana; subdesarrollo; globalización

Clasificación JEL: N37; O11.

' Licenciado en Contabilidad y Finanzas por la Universidad de ciego de Ávila, Cuba. Máster en Finanzas por la Universidad de Mondragón, España. Actualmente Doctorando en economía en de la Universidad Federal de Rio Grande del Sur, Brasil, becario de PEC-PG de CAPES. Teléfono (51)8131 9431. linufeppge07@yahoo.com.br

* Artigo recebido em julho de 2008 e aceito para publicação em agosto de 2008. 


\section{INTRODUCCIÓN}

África Subsahariana (ASS), también conocida como África Negra, aunque muchos consideran esta expresión políticamente incorrecta $\mathrm{u}$ ofensiva, corresponde la región del continente africana al sur del desierto del Sahara. Actualmente está formada por 46 países, dentro de los cuales alrededor de 40 tienen menos de 10 millones de habitantes. La palabra subsahariana se deriva de la convención euro centrista, según el cual el norte esta "arriba" y el sur "abajo" (de allí, el prefijo sub.) La zona de ASS 2 generalmente está dirigida por gobiernos corruptos y autoritarios que no se preocupan en mejorar las condiciones económicas de sus países. Sin lugar a duda, es el continente que presenta la situación más precaria en todos los sectores de la vida: degradación ecológica, guerras intestinas, marginalización económica, migraciones, reestructuración familiar, etc. Como se eso no fuese suficiente, se añade el poco interés de los grandes centros del poder económico en relación a múltiplas áreas, lo que significa automáticamente la reducción de ayuda al desarrollo.

Las negociaciones Norte-Sur vienen llenando la agenda internacional en los años más recientes, en el tema de lucha contra la pobreza, el hambre y contra el fardo de deudas que culminaron con la aprobación de los Objetivos del Desarrollo del Milenio. Sin embargo, la promesa de ayuda del 0,7\% del PNB de los países de la OCDE para los países en desarrollo solo se mantuvo en $0.3 \%$, por lo que no están cumpliendo sus promesas. Venimos asistiendo un agravamiento de los problemas de ASS en contraste con las políticas catastróficas de la globalización llevadas a cabo por las grandes potencias del occidente. La reunión de peritos realizado en Bruxelas del 15 al 17 de Abril del 2004, pretendió iniciar este proceso enfocándolo en tres temas: la deuda, el comercio internacional y la restauración social del Estado en África Subsahariana. Aunque existe mucha literatura y muchos textos dedicados al asunto, infelizmente dedican poco espacio a las ideas provenientes de autores de países en desarrollo como da ASS, lo que aunque no parezca, simplifica la naturaleza de los problemas que eses países enfrentan.

La declaración del Milenio, adoptada por la Asamblea General de Naciones Unidas en Septiembre del 2000, estableció como objetivos

${ }^{2}$ ASS África Subsahariana. 
a alcanzar hasta el 2015, la reducción hasta la mitad de la proporción de la población mundial que viven con menos de un dólar por día y la proporción de la población sofocada por el hambre y sin acceso a agua potable, garantir la educación primaria de todos los niños y jóvenes, reducir en dos tercios la tasa de mortandad de los niños menores de 5 años, invertir el arrastramiento de SIDA y malaria. Son objetivos que no serán alcanzados sin un cambio de actitud de los países industrializados y un aumento significativo de recursos financieros para la ayuda oficial al desarrollo. Este es entonces, uno de los vectores de la conferencia sobre el Financiamiento para el Desarrollo del Consenso de Monterrey, aunque la experiencia pasada no lleva a tener grandes optimismo y se teme que sea una de esas declaraciones de buenas intenciones. La tentativa de entender el subdesarrollo en África junto a modelos ideales con vista a solucionar sus problemas, tiene que ver con el modelo económico basado en el modelo de producción colonial, que en ultima instancia, llevó al surgimiento del trabajo forzado disfrazado de asalariado y la expropiación de tierras para convertirlas en propiedades privadas, concentradas en manos de los europeos o elites locales dominantes y de las grandes compañías comerciales dedicadas a las actividades de exportación.

La mejor lectura del proceso histórico de la intervención política económica no es solo analizar el contexto de la acumulación capitalista y las articulaciones de las potencias imperialistas en la tentativa de consolidar sus intereses económicos, disfrazando la justificativa de implementación de defensa del orden socio-económico, sino también identificar como el continente africano fue articulado entre ideologías opuestas que dividieron el mundo en dos polos económicos y político: el capitalismo y el socialismo. A pesar del fenómeno de globalización dominar los negocios, el reflejo del colonialismo todavía se hace presente en las economías de los países africanos. Lo que quiere decir que tanto los lideres gobernantes cuanto los sectores económicos de los países africanos están siempre sujetos a adaptaciones sucesivas de las exigencias impuestas de afuera, sobretodos oriundos de los centros de poder económico mundial.

Tratándose de la agravación de la crisis en el África Subsahariana, "cuarto mundializada", recalqué lo que siempre había afirmado que era la causa profunda de esta 
innovación: el mantenimiento de África en sus estructuras coloniales (...) que hacía imposible el paso necesario a la intensificación de la agricultura y a la industrialización de apoyo a esta (AMIM, 1999:96)

Con ausencia de modelos de desarrollo, ASS tuvo como única salida política la regionalización económica, con el objetivo de criar un mercado regional para se proteger de la desigualdad en termos de intercambio. Preocupado con el desarrollo del continente, empezaron a surgir políticas regionales llevando los lideres a se organizaren en torno de propuestas para la creación de mercados regionales que pudieran no solo facilitar la vida económica de los productores africanos, pero también fortalecer las relaciones económicas entre los países de cada región, resultando en ultima instancia en aparecimientos de bloco económicos. En este sentido, el artículo sin contar con la introducción, esta dividido en las siguientes partes: el origen histórico de la situación de la región, el sistema económico y financiero, el desarrollo y el subdesarrollo, la globalización y sus consecuencias, el porque aún de la existencia de esta situación de miseria si es reconocido que las condiciones humanas han mejorado más en el último siglo que en todo el resto de la historia de la humanidad, y por último las conclusiones.

\section{ORIGEN HISTÓRICO}

"El trabajo de los pobres es la mina de los ricos"

John Bellers (1696)

Desde hace más de 50 años que se viene hablando de la pobreza en ASS, pero ¿será que en realidad fueron tomadas las medidas correctas y duras para reverter la situación? ¿Será que el occidente se preocupa verdaderamente con el desarrollo de esa parte del planeta, teniendo en cuenta que son sus principales suministradores de materias primas? La cruel verdad es que los corruptos lideres de ASS, son en su mayoría aliados del occidente, porque si así no fuese, como se explica que permanezcan tanto tiempo en el poder, sabiendo que en otras partes, los Estados Unidos y sus aliados hacen intervenciones hasta para expulsar presidentes democráticamente electos. Cuando se analiza la problemática del subdesarrollo y pobreza en 
ASS no hay que olvidar que durante más de 600 años de brutal y inhumana colonización, fue saqueada, robada y transferida para la metrópoli, toda la riqueza que esta zona poseía, pero infelizmente en la literatura excepto los autores de izquierda, este aspecto tan relevante parece ignorada. Sin querer hacer ninguna justificación, lo interesante es que mientras otros países incluso los menos desarrollados de America Latina consiguieron sus independencias hace siglos atrás, los países africanos empezaron a gobernar a sus naciones a partir de la década de 1960, etapa en la cual la mayoría de ellos conseguirán la independencia. Otros todavía solo a medianos de la década de los 70s conseguirán tal merito, concretamente los de la colonia portuguesa. El occidente tiene una gran deuda moral con África debido a tantos años de saqueo, robo y exploración. Un reconocimiento seria un paso gigante para entender el subdesarrollo de ASS, porque es el motivo o la principal causa para toda la situación por la que hoy enfrentan esos países, aunque cabe a los propios africanos invertir la situación. Años después de la independencia, muchos países africanos intentaron insertarse en la economía mundial, pero lo hicieron con graves deficiencias estructúrales en virtud de su malformación producto de siglos de dominación colonial. De hecho, la colonización mas que favorecer el desarrollo de la burguesía africana había asfixiado su potencial, en la medida que podía convertirse en una amenaza política para las metrópolis (Amin, 1999).

La formación del PIB de los países de ASS es poco más de medio millón de dólares por país, sin contar con África del Sur. Esta zona representa cerca de $10 \%$ da población mundial, sin embargo a pesar de unas potencialidades en términos de recurso humanos y materiales, apenas contribuí mundialmente con $1 \%$ do PIB, $1,3 \%$ de las exportaciones y menos de $1 \%$ del VAB industrial. De forma general, la población de ASS presenta los peores indicadores socioeconómicos del mundo. La tabla 1 compara algunos países de ASS que en 2005 exhibieron los valores más altos y bajos del PIB por habitantes expresados en dólares. En ella se incluyen 5 países que muestran los niveles de ingresos más bajos (tanto en el continente como en el mundo), algunos recién emergen de crisis o conflictos como Burundi y Liberia. Las tasas brutas de admisión son bajas: Guinea-Bissau (27\%), Burundi (33\%), Etiopia (51\%). Lo anterior sugiere que en estos países uno de cada tres niños no tiene acceso a la escuela. Los bajos niveles de recursos 
representan la mayor limitación que enfrenta la oferta educativa. Los niveles del PIB per cápita escasamente superan los 100 dólares. Estos bajos niveles de ingreso nacional restringen no solo la los aportes públicos a la educación, sino que también los privados. Así la ayuda externa, representa una forma de fortalecer el nivel de sus recursos. También es esencial tener en cuenta los múltiplos factores que condicionan los recursos humanos que se necesitaran para construir un sistema educativo. Por ejemplo, en Etiopia solamente 36\% de la población declara tener habilidad para leer y escribir. Por lo tanto si solo el hecho de encontrar adultos cualificados con potencial de enseñar es todo un reto, imagínese ese reto con personas no cualificadas.

Con la conquista de las independencias, la mayoría de los países africanos pasaron a enfrentar la necesidad de reestructuración política y económica, una vez que todo lo que había en términos de infraestructuras era construido en función del interés de los colonos así como la necesidad de los nuevos lideres se organizaren en torno de un ideal para engancharse en el contexto político y económico mundial. Entonces estos lideres concientes socio y políticamente del estado de miseria y subordinación brutal monopolista en la que el colonialismo dejó sus países en un mundo de posguerra y bipolarizado, tentaron crear una organización alrededor del cual los estados-naciones recién independientes podrían abrigarse para defender sus intereses políticos y económicos, decisión esta que fue interpretada como un grito de emancipación político y económico de África. El origen de crear un organismo unitario en el continente viene de los ideales del pan-africanismo, empujados por los movimientos de liberalización del colonialismo principalmente a partir de pos-guerra. La OUA es un esfuerzo de conciliación conducido por el emperador de Etiopia, Haille Selassie, quien motivó a los presidentes de los entonces 32 países independientes reunir en Adis-Abeba, del 25 a 26 de Mayo de 1963 para la constitución de la organización. La OUA perseguía los siguientes objetivos: el combate al colonialismo, la defensa del pan africanismo y el combate al apartheid, visando incrementar la cooperación entre los estados miembros, establecer la unidad y la solidariedad de los estados africanos, defender la integridad territorial y la soberanía de sus pueblos. 
Tabla 1. Múltiples contextos que influyen sobre la necesidad de gasto publico en la educación en ASS

\begin{tabular}{|c|c|c|c|c|c|c|c|}
\hline País & $\begin{array}{c}\text { PIBxHab, } \\
\text { U\$S, } \\
2004 \\
\text { (BM) }\end{array}$ & $\begin{array}{l}\text { PIBx } \\
\text { Hab,\$ } \\
\text { PPA, } \\
2004 \\
(B M)\end{array}$ & $\begin{array}{c}\text { Asist } \\
(\% \mathrm{INB}) \\
2004 \\
(\mathrm{BM})\end{array}$ & $\begin{array}{c}\text { Tasa } \\
\text { Alfab } \\
\text { adulto } \\
2000 \mathrm{~s} \\
\text { (UIS) }\end{array}$ & $\begin{array}{c}\text { TMB, } \\
\text { prima. } \\
1999 \\
\text { (UIS) }\end{array}$ & $\begin{array}{l}\text { TMB, } \\
\text { prima. } \\
2005 \\
\text { (UIS) }\end{array}$ & $\begin{array}{c}\text { TBA } \\
\text { último } \\
\text { grado } \\
\text { Educ.Prim } \\
2005\end{array}$ \\
\hline Burundi & 105 & 677 & 54.6 & 59 & 61 & 85 & 33 \\
\hline Etiopia & 113 & 756 & 23.0 & 36 & 59 & 100 & 51 \\
\hline Liberia & 130 & --- & 53.4 & --- & 85 & --- & --- \\
\hline $\begin{array}{l}\text { Guinea } \\
\text { Bissau }\end{array}$ & 137 & 722 & 28.3 & --- & 70 & --- & 27 \\
\hline Malawi & 153 & 646 & 25.9 & 64 & 139 & 122 & 59 \\
\hline Sudáfrica & 3,312 & 11,192 & 0.3 & 82 & 114 & 104 & 96 \\
\hline Botswana & 3,668 & 9,945 & 0.5 & 81 & 102 & 106 & 92 \\
\hline Gabón & 3,860 & 6,623 & 0.6 & 84 & 132 & 130 & 66 \\
\hline $\begin{array}{l}\text { Guinea } \\
\text { Ecuatorial }\end{array}$ & 4,101 & --- & 2.8 & 87 & 132 & 114 & 50 \\
\hline Mauricio & 4,289 & 12,027 & 0.6 & 84 & 105 & 102 & 100 \\
\hline Seychelles & 6,656 & 16,652 & 1.5 & 92 & 116 & 116 & 107 \\
\hline
\end{tabular}

Nota: INB- Índice Nacional Bruto, TBM- Tasa Bruta de Matricula, TBA- Tasa Bruta de Admisión, USIInstituto de Estadística de la UNESCO, PPA- Paridad del Poder Adquisitivo ${ }^{3}$, BM-Banco Mundial Fuente: Base de datos del instituto de estadística de la UNESCO, Banco Mundial 2006

Independientemente de todos esos intentos, ASS continuaba sumergida en tremenda pobreza, guerra y miseria; provocando la necesidad de continuar la búsqueda de soluciones para mejorar la situación. En épocas más recientes los dirigentes africanos capitaneados por el presidente surafricano Thabo M'beki, de Senegal Abdoulaye Wade, de Argelia Addelaziz Bouteflika, de Nigeria Olesegun Obasanjo y de Egipto Osni Moubarak, crearon la NEPAD ${ }^{4}$, y que a partir de octubre del 2001 se torno oficialmente como el nuevo cuadro común del desarrollo de África. Esta organización visa

${ }^{3}$ Este concepto (PPA) refleja con mayor exactitud el valor real de las inversiones realizadas por los gobiernos y las familias. Representa una tasa de conversión que elimina las diferencias de los precios observados entre los países. Significando que una suma determinada de dinero expresadas en dólares PPA podrá comprar la misma canasta de bienes y servicios en cualquier país del mundo.

${ }^{4}$ NEPAD - Nueva Asociación Para el Desarrollo. 
promover una mayor integración de los gobiernos, del sector privado, la sociedad civil e el parlamento, motivando la creación de los consensos sobre cuestiones nacionales. Asimismo, el legado social colonial dejó mucho que desear, con lo que algunos gobiernos independientes dedicaron crecientes sumas a prever prestaciones sociales como sanidad básica y educación primaria. Pero también la falta de de preparación, la inexperiencia en la gestión del nuevo Estado llevó a algunos casos a despilfarro innecesarios. Surge entonces una cuestión para la reflexión: ¿A quien le interesa esta idea de regionalización se los países signatarios continúan siendo dependientes económicamente y tomadores de precios en el comercio internacional? La respuesta a esta cuestión lleva a buscar descubrir los entendimientos que se cierran en torno de los intereses económicos entre los países africanos y sus ex metrópolis, según Mamadu Bari (2006).

El marasmo social y la pobreza, acentuada por los Planes de Ajuste Estructural constituyen la chispa que enciende conflictos latentes que llegan a degenerar conflictos armados, lo que empeora aún más la situación (Gemma y Colom (2003), convirtiendo la situación de endeudamiento todavía más dramática. Con eso, mas allá de las criticas genéricas del FMI y del BM, quienes considerándose portadores de la única vía de salida para África, imponían sus programas de ajuste diseñados en Washington, sin apenas discutirlos con los técnicos y políticos locales, influyendo mucho la condicionalidad de los prestamos otorgados, los cuales redundaba en un divorcio flagrante entre realidad y modelos. En 1996, el FMI y el BM aprobaron con el apoyo de G-7, los términos de la iniciativa de alivio de la deuda externa para 41 países subdesarrollados, los $\mathrm{HIPP}^{5} \mathrm{o} \mathrm{PPAE}^{6}$ con el objetivo de alcanzar unos niveles de deuda sostenible con el fin ultimo de estimular el crecimiento económico y la reducción de la pobreza. A pesar de la mencionada especificidad periférica, en términos económicos y políticos del grueso de PPAE del ASS, las instituciones financieras siguen centrando los problemas financieros de la región en consideraciones que a menudo obvian tal especialidad:

(...) muchos países pobres, especialmente en África al sur de Sahara, siguen padeciendo niveles inaceptables de pobreza y pesadas cargas de endeudamiento debido a una combinación

${ }^{5}$ HIPP-Heavily Indebted Poor Contraes

${ }^{6}$ PPAE Países Pobres Altamente Endeudados 
Las raíces históricas del atraso económico en África Subsahariana

\begin{abstract}
de factores, entre ellos la aplicación de políticas imprudentes de gestión de la deuda externa, la falta de perseverancia en el ajuste estructural y la reforma económica, el deterioro de la relación real de intercambio y una gestión desacertada del gobierno (ANDREWS et al., 1999).
\end{abstract}

Los requisitos para que un país pueda acceder a la iniciativa, es decir, aquellos para que sea considerado como país elegible, son altamente restrictivos, quedando limitada esta oportunidad a un conjunto de países muy pobres, muy endeudados y marginados de los flujos financieros internacionales de capital. Concretamente las condiciones son las siguientes: i) que los países estén habilitados a acceder a las ventanillas blandas de las instituciones financieras internacionales, es decir, a los préstamos de la AIF- del grupo del BM-y el servicio reforzado de ajuste estructural (SRAE), ii) que los países estén aplicando los programas de ajuste diseñados por estas instituciones, iii) la incapacidad de lograr la sostenibilidad de la deuda externa después de la aplicación de los mecanismos tradicionales de alivio de la deuda externa.

La cuestión de salud es uno de los graves problemas de la región, donde se destacan: Enfermedad del sueño: amenazando mas de 60 millones de personas en 35 países en ASS y la mayoría de esas personas no tienen acceso a centros de salud; Malaria: enfermedad presente en casi 100 países y amenaza a $40 \%$ de la población mundial, donde anualmente 500 millones de personas son infectados, mayoría también esta en ASS, donde según los datos estadísticos, se estima que $90 \%$ de los casos mundiales y $90 \%$ de toda la mortandad por esa enfermedad acontecen en ASS ( 2 millones de personas mueren de esa enfermedad): $A I D S$ : desde que los primeros casos de síndrome de inmunodeficiencia adquirida fueron detectados en 1981, África es el continente que mas sufre con la enfermedad, según cifras publicadas por el programa de Naciones Unidas contra el Aids. En algunos países de África meridional más de una cuarta parte de la población es seropositiva. La prevalencia se ha estabilizado en la región, pero sigue siendo elevada.

Es necesario referirnos aquí a la concepción de la pobreza dominante en las instituciones internacionales que a su vez guía el diseño de las políticas a implementar. Ello es relevante en la medida que el concepto de desarrollo en cierta manera ha quedado reducido al de pobreza, determinando no solamente las opciones estratégicas de estas instituciones sino también construyendo 
un cuerpo ideológico, con notable influencia, que configura una determinada concepción de desarrollo. La definición económica de la pobreza, de acuerdo con la cobertura de los mínimos en términos de consumo, y medido mediante el indicador tradicional la línea de la pobreza basada en un dólar per capita al día, sigue estando presente en el enfoque del BM y las iniciativas que este emprende. Ello impide avanzar en la concepción de la pobreza más amplia y multidimensional, como serian aquellas centradas en la perspectiva de capacidad, basada en la situación no solamente empobrecida en que la persona vive sino también en la carencia de oportunidad real para vivir mejor.

\section{SISTEMA ECONÓMICO Y FINANCIERO}

\subsection{Sistema Económico}

La producción y su destino todavía se encuadran en el ciclo de autosubsistencia de la mayoría de los países africanos. El modo de producción era y aún es basada en mono cultura con base en el modelo primario exportador. Amin (1977), analizando el sistema fundíario de África esclarece que el proceso de expansión de propiedad fundiaria estructurada con base en el modo de producción colonial tanto en África como en America Latina y Asia estuvo subordinado a los respectivos modelos de exportación, implantados por cada potencia colonizadora, y por lo tanto, dependiente del llamado exclusivo metropolitano. Dicho sea de paso, no hubo ruptura social análoga como la verificada en otras partes del mundo, pero si, ampliar y perpetuar la economía de trueque.

Las funciones de la sociedad rural era suministrar productos agrícolas baratos, permitiendo la reducción de valor de la fuerza de trabajo. Las exportaciones de capitales y de los productos manufacturados proporcionan el aumento de lucros y por consiguiente, el aumento de riqueza en los países industrializados, eso porque en las colonias de ASS los impuestos eran altamente cobrados, los precios de las tierras y de los salarios eran bajísimos y las materias primas eran baratas, o sea, este proceso de transferencia brutal de renta permitió la aceleración de la acumulación de capital en las colonias y la expansión del capitalismo. Esta misma expansión vía colonialismo fue la originaria de un mercado mundial, donde las colonias 
suministradoras de minerales y de géneros agrícolas eran complemento de la economías desarrolladas. Sin embargo, ese mercado mundial no representó beneficios para las colonias, ya que las vendas de sus productos no se realizaban conforme las leyes de la oferta y demanda, pero si a través de una relación forzosa, ya que la metrópoli con su poderío militar imponía los precios de los productos. La comercialización de los productos coloniales se quedaba a cargo de las compañías europeas que se apropiaban de la mayor parte del lucro, restando la menor parte a la burguesía colonial. $¿$ Que es lo que se quedaba para las poblaciones creadoras de estas riquezas? Apenas quedaba la pobreza a pesar de abundantes recursos naturales, el hambre a pesar de tierras agrícolas, la miseria a pesar del concepto de familia grande africana basada en la agricultura solidaria, y todos los otros tipos de explotación del hombre por el hombre.

Todavía con todo esto, los líderes africanos aún mantenían firmes sus ideales del desarrollo. En este contexto, bajo la égida de la ONU se creó la Comisión Económica para África (CEPA). Sin embargo la CEPA no tuvo un desempeño incentivador para la creación de forum científicos o académicos que ayudara a organizar debates en torno de los cuales se pudiesen elaborar teorías económicas, como las hechas por la CEPAL en America Latina, una escuela de pensamiento económico capitaneado por el economista argentino Raúl Prebisch rodeado de otros economistas como Celso Furtado, Aníbal Pinto, Maria da Conceição Tavares entre otros, cuyo objetivo es estudiar las desigualdades y la pobreza del continente latinoamericano. En África el intento de construcción de un modelo parecido, fue un autentico fracaso. Actualmente el funcionamiento de la economía africana esta caracterizada por: economías predominantemente agrícolas excepto Sudáfrica, exportaciones basadas en bienes primarios, dependencia tecnológico y manufactura externa, así como de la existencia de dos grupos fundamentalmente, i) el B5 formada por Sudáfrica, Argelia, Nigeria, Maruecos y Egipto, ii) El constituido por los 11 países exportadores de petróleo.

Observando la tabla 2, se ve que es la zona que menos exporta mercancías, por la existencia de muchos problemas, como: ritmo de crecimiento insuficiente, cayendo en casi 7\% menos de lo permitido. Las mercancías exportadas por un solo país como China superan al total de ASS. Entonces habrá que buscar otros incentivos para este aspecto. 
Analizando la tabla 3 y viendo el desempeño crítico de la economía de estos países, así como las reservas financieras, se concluirá que es difícil el desarrollo en ASS teniendo en cuenta que poseen menos recursos de lo que tienen que pagar (Bari, 2006). Entonces para sus sobre vivencias, es clara que ellos estarán trabajando para pagar el servicio de la deuda como medida de garantizar la entrada de recursos financieros. Quizás sea, el motivo por el cual en la tabla 3 se observa las variaciones positivas del PIB de algunos de estos países por encima de la media mundial. Y aunque algunos ya tienen sus deudas perdonadas, aun es crucial la necesidad de aporte complementar de recursos financiero a sus gobiernos.

Tabla 2: Exportaciones Mundiales de Mercancías por Regiones, 2001

\begin{tabular}{c|c|cc}
\hline \multirow{2}{*}{ Región } & Valor & \multicolumn{2}{|c}{ Partes } \\
& 2001 & 1990 & 2001 \\
\hline Mundo: & 5984 & 100,0 & 100,0 \\
\hline Estados Unidos & 731 & 11,6 & 12,2 \\
\hline Unión europea (15) & 2291 & 44,4 & 38,3 \\
\hline América Latina & 347 & 4,3 & 5,8 \\
\hline África: & 141 & 3,1 & 2,4 \\
\hline Sudáfrica & 29 & 0,7 & 0,5 \\
\hline Asia & 1497 & 21,8 & 25,0 \\
\hline Japón & 403 & 8,5 & 6,7 \\
\hline China & 266 & 1,8 & 4,4 \\
\hline
\end{tabular}

Nota: Cifras en miles de millones de dólares y porcentaje Fuente: Elaboración propia a partir de los datos de OMC 
Tabla 3. Indicadores económicos de algunos países de ASS, 2004

\begin{tabular}{l|c|c|c|c|c}
\hline País/indicadores & $\begin{array}{c}\text { Hab. } \\
\left(10^{6}\right)\end{array}$ & $\begin{array}{c}\text { Área } \\
\left(10^{3}\right)\end{array}$ & $\begin{array}{c}\Delta \mathrm{PIB} \\
\%\end{array}$ & $\begin{array}{c}\text { Reserva } \\
\left(10^{9}\right) \mathrm{U} \$ \mathrm{~S}\end{array}$ & $\begin{array}{c}\text { Deud. Ext. } \\
\left(10^{9}\right) \mathrm{U} \$ \mathrm{~S}\end{array}$ \\
\hline Angola & 14,3 & 1,246 & 1,5 & 8,4 & 9,2 \\
\hline Gabón & 1,3 & 0,268 & 1,2 & 0,149 & 3.3 \\
\hline Guinea-Bissau & 1,3 & 0,036 & 4,5 & 0,070 & $\mathrm{nd}$ \\
\hline Mozambique & 18,9 & 0,799 & 7,0 & 0,818 & 1.0 \\
\hline Namibia & 1,9 & 0.824 & 3,0 & 0,323 & 0,3623 \\
\hline Nigéria & 140,0 & 0,924 & 3,8 & 9,9 & 29,1 \\
\hline São Tomé & 0,140 & 0,001 & 5,0 & 0,024 & $\mathrm{Nd}$ \\
\hline Senegal & 9,8 & 0,197 & 5,6 & 0,425 & $\mathrm{Nd}$ \\
\hline Sudáfrica & 45,7 & 1,219 & 1,9 & 6,5 & 5,9 \\
\hline
\end{tabular}

Fuente: Bari, Mamadu SISCOMEX, 2004

Un aspecto positivo a tener en cuenta, es que la producción local puede ser una de las formas más estables de mejorar la vida de la población, la seguridad alimentar para contribuir al desarrollo económico a largo plazo, ya que la seguridad alimentar, también esta directamente ligada a las cuestiones de la pobreza. En ASS los más pobres viven en su gran mayoría en zonas rurales, obteniendo sus sustentos diarios directa o indirectamente de la agricultura. Por lo tanto invertir en áreas rurales y reducir la migración para las grandes ciudades, así como invertir los rendimientos generados localmente, permitiría el beneficio tanto el país como de la población local.

La producción y el consumo de alimentos en ASS están relacionados íntimamente con el sistema socio-cultural. Mientras las exportaciones del mundo desarrollado, son dominadas por cereales y no incluyen por ejemplo el "Yam o yuca", culturas que más de 1/3 de la población de ASS depende. Un grande numero de de mercancías con lo que los más carentes en ASS alimentan, no son producidas por países industrializados (tabla 4). Quizás a longo plazo, los cambios alimentares en los países ricos puede resultar en cambios donde entran mas alimentos producidos en los países de ASS, y eso seria una buena oportunidad para ampliar sus exportaciones. 
Tabla 4. Alimentos importantes en ASS

\begin{tabular}{c|c}
\hline Alimento & Kg./Ano \\
\hline Yuca & 103 \\
\hline Maíz & 40 \\
\hline Plátano & 28 \\
\hline Yam & 28 \\
\hline Leche & 27 \\
\hline Mapira & 23 \\
\hline Carne & 11
\end{tabular}

Nota: Per capita kg/ano

Fuente: Elaboración propia según los datos de FOSTAT

\subsection{Sistema Financiero}

Aquí la cuestión central tiene que ver con el acceso al financiamiento. Un aspecto crucial para el desarrollo en las economías en desarrollo, donde los bancos desempeñan un papel importante en la determinación de los niveles de vida de las economías. Los bancos tienen la capacidad de estimular y colectar el ahorro de una sociedad y distribuirla como insumos para las actividades económicas, y mediante este proceso el sector bancario puede determinar y alterar la trayectoria de progreso económico en los países que no cuentan con fuentes alternativas de financiamiento y mercado de capitales bien desarrollados como es el caso de ASS. El sector bancario de ASS es subdesarrollado, cuenta con menos créditos y márgenes de intermediación muy altas, que se traduce en que el sistema financiero en ASS es muy vulnerable. El crédito bancario es muy escaso y el nivel promedio otorgado al sector privado en la región en el periodo analizado es tan solo de $21 \%$ de PIB (tabla 5), una tasa significativamente baja en comparación con otras regiones en desarrollo, como el Medio Oriente y África del Norte (43\%) o America Latina y Caribe (28\%), eso sin mencionar el de los países desarrollados que presentan una cifra de 84\%. Por lo tanto el mercado de crédito de la región es muy pequeño. Entonces si el crédito al sector privado se escasea, se vuelve muy complicado el 
desarrollo, porque como no existe dinero para operar nuevas inversiones o innovaciones, se buscarían otras vías quizás más costosas.

Tabla 5: Desarrollo Financiero por Regiones, años noventa

\begin{tabular}{l|c|c|c|c}
\hline \multicolumn{1}{c|}{ Región } & $\begin{array}{c}\text { Número } \\
\text { de países }\end{array}$ & $\begin{array}{c}\text { Crédito } \\
\text { al sector } \\
\text { privado } \\
(\% \text { PIB })\end{array}$ & $\begin{array}{c}\text { Crédito y } \\
\text { capitalización } \\
\text { de mercados } \\
(\% \text { PIB })\end{array}$ & $\begin{array}{c}\text { PIB per. } \\
\text { Capita 1995 } \\
\text { (dólares) }\end{array}$ \\
\hline Países desarrollados & 24 & 84 & 149 & 23815 \\
\hline Asia del Este y pacifico & 10 & 72 & 150 & 2867 \\
\hline Medio Oriente y norte de África & 12 & 43 & 80 & 4416 \\
\hline America Latina y Caribe & 20 & 28 & 48 & 2632 \\
\hline Europa del Leste y Asia Central & 18 & 26 & 38 & 2430 \\
\hline África Subsahariana & 13 & 21 & 44 & 791 \\
\hline Sur de Asia & 6 & 20 & 34 & 407 \\
\hline Nota: Promedio simples pra
\end{tabular}

Nota: Promedio simples por región para los años noventa.

Fuente: Informe del BID 2004 y elaboración propia.

La tabla 6 muestra los promedios de los márgenes de intermediación (valores nominales) en diferentes regiones del mundo. ASS presente los márgenes de intermediación más elevado (10,6\%). Mirando al otro extremo donde están los países desarrollados, solo es de 2,9\%. El subdesarrollo del sector bancario no solo se traduce en menos créditos, sino también en margen de intermediación mas altos, es decir, en la diferencia entre la tasa de interés que cobra a los prestatarios y la tasa que se paga a los depositantes y por consiguiente en la tasa de préstamo más altas y en menor rendimiento neto del ahorro. El diferencial entre estos costos refleja: i) la eficiencia y el poder del mercado del sector bancario, ii) el riesgo de incumplimiento en el reembolso del préstamo, iii) los riesgo de liquidez, de la tasa de cambio y de otra índole, iv) las disposiciones en vigor y v) los impuestos explícitos e implícitos de los bancos. 
Tabla 6: Diferencia de Tasa de Interés e Eficiencia por Regiones, 1995-2002

\begin{tabular}{l|c|c|c|c}
\hline \multicolumn{1}{c|}{ Región } & $\begin{array}{c}\text { Número } \\
\text { de países }\end{array}$ & $\begin{array}{c}\text { Diferencias } \\
\text { de tasas de } \\
\text { interés (\%) }\end{array}$ & $\begin{array}{c}\text { Costos } \\
\text { administrativos } \\
(\% \text { de activos })\end{array}$ & $\begin{array}{c}\text { Crédito al } \\
\text { sector privado } \\
\text { (\% de PIB) }\end{array}$ \\
\hline África Subsahariana & 32 & 10,6 & 5,1 & 15 \\
\hline Europa del Este y Asia Central & 23 & 8,8 & 5,0 & 26 \\
\hline America Latina y Caribe & 26 & 8,5 & 4,8 & 37 \\
\hline Asia del Este y Pacifico & 16 & 5,1 & 2,3 & 57 \\
\hline Sur de Asia & 5 & 4,6 & 2,7 & 23 \\
\hline Medio Orientey Norte de África & 10 & 4,0 & 1,8 & 38 \\
\hline Países desarrollados & 30 & 2,9 & 1,8 & 89 \\
\hline
\end{tabular}

Nota: valor de la media para el periodo de 1995-2002

Fuente: Informe del BID 2004 y elaboración propia.

En lo que concierne a la volatilidad del crédito real (ver tabla 7) medido como la desviación estándar del crecimiento del crédito real de un país durante el periodo en cuestión, ASS presenta la segunda cifra más alta, solo superada por Europa de Este y Asia, pero estos por razones obvias, ya que estos países sufrieron drásticos cambios económicos en el periodo después del desmoronamiento del régimen socialista. Un desarrollo financiero inicial más alto, pude dar lugar a un posterior crecimiento del PIB concluyendo que el desafío financiero realmente induce al crecimiento económico. De hecho, existe una alta correlación entre el crédito bancario y el PIB per capita, así los países con sectores bancarios pequeños como los de ASS tienen niveles más bajos del desarrollo. Esa fuerte correlación es una clara señal del vínculo existente entre el sector financiero y el económico. Desde el punto de vista teórico el desarrollo financiero pude dar lugar al desarrollo económico al mejorar la distribución de ahorro en la economía, pero también el desarrollo económico mediante la creación de nuevas instituciones e infraestructuras necesaria puede promover el desarrollo financiero. Entonces la estabilidad financiera es crucial para el desarrollo de los países de ASS. 
Tabla 7: Volatilidad del crédito por región, 1990-2002

\begin{tabular}{l|c|c|c|c}
\hline \multicolumn{1}{c|}{ Región } & $\begin{array}{c}\text { Número } \\
\text { de países }\end{array}$ & $\begin{array}{c}\text { Volatilidad } \\
\text { del crédito } \\
\text { sin ajustes } \\
(\%)\end{array}$ & $\begin{array}{c}\text { Volatilidad del } \\
\text { crédito ajustado } \\
\text { por la volatilidad } \\
\text { del PIB }(\%)\end{array}$ & $\begin{array}{c}\text { Volatilidad del } \\
\text { crédito ajustada } \\
\text { por shocks } \\
\text { externos (\%) }\end{array}$ \\
\hline África Subsahariana & 37 & 18 & 17 & 19 \\
\hline $\begin{array}{l}\text { Europa del Este y Asia } \\
\text { Central }\end{array}$ & 20 & 21 & 16 & 18 \\
\hline America Latina y Caribe & 31 & 14 & 15 & 12 \\
\hline Asia del Este y Pacifico & 16 & 14 & 14 & 08 \\
\hline Sur de Asia & 16 & 14 & 12 & 06 \\
\hline $\begin{array}{l}\text { Medio Oriente y Norte de } \\
\text { África }\end{array}$ & 06 & 09 & 08 & 12 \\
\hline Países desarrollados & 24 & 06 & 12 & 14 \\
\hline
\end{tabular}

Fuente: Informe del BID 2004 y elaboración propia

\section{DESARROLLO Y SUBDESARROLLO}

Cuando se compara un mundo de industrias monopolizadas con un mundo de competencia imperfecta, se observa que las técnicas de producción pueden mejorar considerablemente cuando aumenta el tamaño de la unidad de control de la industria. Pero se observa que un aumento del tamaño de la unidad del control provoca un aumento de la desigualdad de la distribución de la riqueza. El problema del mundo de los monopolistas se reduce, pues, al conocido dilema de la eficiencia y la justicia Joan Robinson, the Economics of Imperfect Competition (1933)

Durante mucho tiempo ha prevalecido la idea de concebir al subdesarrollo únicamente como un fenómeno de naturaleza económica. Si bien que durante los años 40 y 50 del pasado siglo se difundieron teorías que asociaban los problemas del subdesarrollo a factores de carácter sociológicos, psicológicos, étnicos e incluso climáticos. Lo cierto es que rápidamente fueron olvidadas frente al empuje de aquellas teorías que 
concentran su atención en la identificación de obstáculos económicos, en particular asociados con bajas tasas de crecimiento de sus economías. Si en la actualidad tuviesen en cuentas esos factores olvidados, el tema del subdesarrollo de ASS tendría otra vertiente en relación al foco del problema. El subdesarrollo es un fenómeno multidimensional, lo que equivale considerar las dimensiones no solo económicas, sino también las políticas, las sociales las culturales y las ambientales.

Generalmente existe equivoco por parte de occidente a la hora de interpretar el subdesarrollo de ASS. Consideran que los métodos y teorías por ellos desarrollados son validos para todos los países, al asumirse que en la economía, los agentes no interesa si es un gerente de una gran empresa norteamericana o un campesino de Guinea, actuarían guiados por sus intereses económicos, por lo que no se hace necesario disponer de herramientas analíticas especificas para interpretar a las economías subdesarrollados. En todo caso, de lo que se trata, según la tradición neoclásica, es de la aplicación sus principios de análisis en la solución de los problemas de esas economías. Las políticas del FMI aplicadas en numerosos países de ASS desde los años 80, descansan en el razonamiento anterior; formuladas con recetas validas para cualquier tipo de países, ni siquiera previenen la magnitud de los efectos sociales que traería aparejada su aplicación.

El economista argentino Raúl Prebish, señaló en una ocasión que el problema fundamental de desarrollo de una estructura subdesarrollada, no es simplemente crecer económicamente, sino transformar su estructura productiva de modo a alcanzar una capacidad autónoma de crecimiento y reorientar su sistema económico en función de satisfacer los objetivos nacionales. Tales objetivos tiene que ver con las soluciones más importantes del subdesarrollo de la economía de la periferia: Desempleo elevado, derivado de lo que la oferta de empleo es insuficiente para dar la respuesta a la creciente población activa; Desequilibrio externo, resultado de que los gastos por concepto de importaciones anualmente son superiores a los ingresos por exportaciones, generando procesos de endeudamiento externo; Deterioro de la relación de intercambio, resultante de que los precios de los productos de exportaciones de mantienen altos.

Cualquier economía que presenta esta situación tenderá a aumentar el volumen de exportaciones para compensar la caída de los precios y así 
mantener el nivel de importaciones. Algunos economistas de la teoría de la dependencia parten de algunos enfoques en relación a diversas metodologías para explicar el subdesarrollo, colocando la dependencia como el factor clave. Lo distintivo de ese enfoque es asumir que no es posible comprender el subdesarrollo si no comenzamos por aprender cómo su historia económica y social pasada pudo provocar su actual desarrollo, y que la mayoría de los estudios sobre el desarrollo y subdesarrollo no tienen en cuenta las relaciones económicas, y otras, entre las metrópolis y sus colonias económicas en el transcurso de la expansión y del desarrollo mundial del sistema mercantil capitalista.

De esta manera, Samir Amín, uno de los actores de la teoría de dependencia, rechaza la tesis de que los países subdesarrollados tienen que ajustarse a los criterios de racionalidad económica dictadas por la globalización neoliberal o, de lo contrario, perecerán. En su opinión, en cada momento histórico, las relaciones internas de una sociedad deberían subordinarse a los objetivos que dimanan de su desarrollo interno, de modo que se orienten a satisfacer las necesidades de las masas. Existen infinitas interpretaciones acerca de lo que es en realidad el subdesarrollo en la literatura. Para el buen engranaje de este trabajo, se escogió la idea de Ernesto Guevara. El Guerrillero cubano-argentino (Colectivo de Actores, 2006) quien empleando una original analogía, señaló que

(...) un enano de cabeza enorme y el tórax henchido es subdesarrollado en cuanto a que sus débiles piernas o sus cortos brazos no articulan con el resto de su anatomía; es el producto de un fenómeno teratológico que ha distorsionado su desarrollo. Eso es lo que en realidad somos nosotros, los suavemente llamados subdesarrollados, en verdad países coloniales, semicoloniales y dependientes.

Una deducción del refrán de Ernesto Guevara, muestra claramente que asoció el subdesarrollo con deformaciones en la economía y la sociedad de un determinado país ocurridas a lo largo de un proceso histórico, signado por el colonialismo y el imperialismo que truncó el camino de la industrialización y con ello, fueron alteradas las condiciones $\mathrm{y}$ formas de desarrollo en adelante. 


\section{LA GLOBALIZACIÓN Y SUS CONSECUENCIAS PARA ÁFRICA SUBSAHARIANA}

La globalización, forma como las compañías transnacionales (TNC) promueven los desiguales intercambios comerciales, se caracteriza por la hegemonía de una superpotencia mundial como lo es Los Estados Unidos de Norteamérica. Basado en esta visión, se suele decir que las crisis de ASS es fruto de la globalización y está directamente ligado a las políticas de ajuste estructural (PAE) del FMI/BM focalizados en el balance de pago y en las variables macroeconómicas, que pos su vez están en el origen de guerras civiles como en Sudan, Sierra Leona, Guinea-Bissau o actualmente en Kenya. La convergencia entre los países desarrollados y ASS acontece por causa del área de la actividad protegida y subsidiada por los países desarrollados y por el deterioro del término de intercambio de las exportaciones de los países de ASS.

En esta orden de idea, añadir todavía la presión de las TNC europeas para el desaparecimiento de la no reciprocidad de acuerdos $\mathrm{ACP}-\mathrm{UE}^{7}$ de Cotonou que visa cumplir las orientaciones de la $\mathrm{OMC}$, evidenciando que lo que esta en juego es la agenda de la globalización. A modo de ejemplo, la iniciativa de UE TSA (todo salvo armas) para los países menos desarrollados (PMD) tiene innumeras excepciones, y manteniendo los subsidios proteccionistas de PAC (programa de ayuda al crecimiento), los productores africanos ven dificultadas sus accesos a los mercados de los países industriales fruto del apoyo de los agricultores de los EE.UU., Canadá y UE, queriendo decir claramente que la liberalización es para África y no para los productores de los países desarrollados que protegen sus mercados.

Analizando la tabla 8, es de señalar que las tendencias para ASS son una constante marginalización económica y comercial, ya que ninguno de sus países aparece en la lista de beneficios de la globalización. ASS exporta materias primas e importa productos manufacturados, con lo que existe un claro desregulación de intercambio comercial, ya que al fin y al cabo, ASS consume lo que no produce y produce lo que no consume. Las políticas de los países desarrollados en los países de ASS es la lucha por la extensión de los

${ }^{7}$ ACP-EU- África Caribe y Pacifico - Unión Europea 
mercados, en especial los mercados de prestaciones de servicios, llevando este aspecto más importante aun que la liberalización de comercios de bienes.

Tabla 8: Principales Economías Receptoras de Inversión Extranjera Directa en 2001 (Cifras en miles de millones de dólares)

\begin{tabular}{|c|c|c|c|c|c|}
\hline Países Desarrollados & 1997 & 1998 & 1999 & 2000 & 2001 \\
\hline Estados Unidos & 103,4 & 174,4 & 283,4 & 300,9 & 124,4 \\
\hline Inglaterra & 33,2 & 74,3 & 87,5 & 116,5 & 53,8 \\
\hline Francia & 23,2 & 30,9 & 46,7 & 42,9 & 52,8 \\
\hline Bélgica y Luxemburgo & 11,9 & 22,7 & 133,1 & 245,5 & 51,9 \\
\hline Holanda & 11,1 & 36,9 & 41,3 & 52,4 & 50,5 \\
\hline Alemania & 12,2 & 24,6 & 54,7 & 195,1 & 31,8 \\
\hline Canadá & 11,5 & 22,8 & 24,4 & 66,6 & 27,4 \\
\hline España & 7,7 & 11,8 & 15,7 & 37,5 & 21,7 \\
\hline Italia & 3,0 & 2,6 & 6,9 & 13.4 & 14,8 \\
\hline Suecia & 10,0 & 19,5 & 60,0 & 23,3 & 12,7 \\
\hline \multicolumn{6}{|l|}{ Países en Desarrollo } \\
\hline China & 44,2 & 43,7 & 40,3 & 40,7 & 46,8 \\
\hline México & 14,1 & 11,9 & 12,5 & 14,7 & 24,7 \\
\hline Hong Kong & 11,4 & 14,7 & 24,5 & 61,9 & 22,8 \\
\hline Brasil & 18,9 & 28,8 & 28,5 & 32,7 & 22,4 \\
\hline Bermuda & 2,9 & 5,3 & 9,4 & 10,9 & 9,8 \\
\hline Polônia & 4,9 & 6,3 & 7,2 & 9,3 & 8,8 \\
\hline Singapura & 10,7 & 6,3 & 11,8 & 5,4 & 8,6 \\
\hline Sudáfrica & 3,8 & 0,6 & 1,5 & 0,8 & 6,6 \\
\hline Chile & 5,2 & 4,6 & 9,2 & 3,6 & 5,5 \\
\hline Republica Checa & 1,3 & 3,7 & 6,3 & 4,9 & 4,9 \\
\hline
\end{tabular}

Fuente: Elaboración propia a partir de los datos de UNCTAD

Para los especialistas, en la globalización la cuestión de integración de ASS, tanto a través de colocación de sus mercancías como por la recepción 
de nuevos productos, servicios y tecnologías, también se presentan menos optimistas ante la disminución de los flujos de inversión extranjera, por el constante aumento de la deuda externa y el fracaso de las políticas de reajuste estructural, dictadas por el FMI/BM. Según Chang (2003) existen pocas justificaciones para argumentar que las TNCs son benéficas para el desarrollo económico de los países en desarrollo. Existe un reciente consenso que aceptando el pacote financiero y tecnológico, de que las habilidades gerenciales y otras potencialidades ofrecidas por las TNCs pueden no ser tan buenas para el desarrollo industrial a largo plazo como lo son las empresas nacionales. Por eso, se incentiva la construcción de los modelos o pacotes propios, característicos de los países, utilizando habilidades gerenciales con alguna que otra contratación necesaria. La gran cuestión que se levanta no es de saber si la globalización es o no benéfica para todo el mundo, pero si la equidad en la distribución de sus beneficios entre los países y entre los individuos, o sea, los beneficios se distribuyen de forma asimétrica.

\section{6. ¿PORQUE AÚN EXISTE ESTA SITUACIÓN DE MISERIA SI LAS CONDICIONES HUMANAS HAN MEJORADO MUCHO EN EL ÚLTIMO SIGLO?}

En el mundo más de 12 millones de niños mueren anualmente en los países subdesarrollados de enfermedades curables, 325 millones de niños de esos países no tiene acceso educación; mas de 850 millones son analfabetos; 1300 millones de personas viven en externa pobreza y 1075 millones viven con menos de un dólar al día; $86 \%$ de consumo total es realizado por $20 \%$ de la población mundial; más de mil millones de seres humanos viven en esa zona sin agua potable; 70 millones de personas afectadas por el HIV-Sida están condenados a morir en los próximos años. Sin embargo aún con este catastrófico panorama, el presupuesto militar de los EUA en 2003 fue de 380 mil millones de dólares, o sea, 3,2\% de su PIB y apenas $0.11 \%$ fue destinado para ayuda al desarrollo y la UE apenas destinó $0.33 \%$ de ayuda al desarrollo. ¿Entonces a que va todo eso? ¿Existe un compromiso por parte del occidente?

La humanidad posee conocimientos y recursos necesarios para prevenir y evitar todas estas situaciones. Lo increíble es que hasta el Banco Mundial reconoce que esta situación de miseria persiste a pesar de que las condicio- 
nes humanas han mejorado más en el último siglo que en todo el resto de la historia de la humanidad: la riqueza mundial, los contactos internacionales y la capacidad tecnológica son ahora mayores que nunca. Pero la contradicción si sintetiza en que los beneficios de toda riqueza y tecnología van para los países llamados desarrollados. Es evidente que el actual orden económico internacional, que genera desigualdades e injusticias, funciona solamente para una minoría de población mundial y excluye de los beneficios a la gran mayoría. Las informaciones estadísticas señalan que en los veinte últimos años, se verificó un aumento de desigualdades entre los países y en general, lo mismo sucede con la distribución de la renta entre los individuos dentro de cada país. En 1960 a titulo de ejemplo, el rendimiento de los 20\% más ricos de la población de mundo era 30 veces el rendimientos de los $20 \%$ más pobre; hoy es 90 veces más. La justicia y la solidariedad social, independientemente de sus dimensiones locales y nacionales, no pueden dejar de tener también una dimensión internacional, como es costumbre decir: la orden económica internacional tiene que tener corazón.

En un mundo globalizado, la estrategia más adecuada para el combatir la desigualdad y la exclusión social dentro de un país, radica en la adopción de políticas públicas dirigidas á igualdad de oportunidades de los individuos, principalmente a través de reforma agraria, educación, formación profesional, de salud, habitación y seguridad. Los países ricos deberían comprender que la solidariedad y la redistribución de rendimientos a escala mundial serian benéficas para su propia seguridad. Un mundo de grandes desigualdades del desarrollo entre los países, en que algunos se encuentran en situaciones de la más pura pobreza, es un mundo inseguro e inestable. Para muchos países de ASS no basta solo la adopción de políticas correctas para conseguir recolectar los beneficios de la globalización. Son países de rendimiento bajo, con una dotación de factores físicos y humanos extremadamente débil o con niveles de endeudamiento insostenible que los impide vencer la "armadilla de la pobreza" donde están atrapados sin una extraordinaria ayuda de los países mas ricos. Desde el punto de vista ético, lo grave no es la ausencia del incumplimiento del pacto de Joanesburgo, en la cumbre de la tierra para los compromisos de ayuda al desarrollo por parte de los países industrializados hasta el $0,7 \%$ de sus PIB como se hizo mención en la introducción de este trabajo, pero si el hecho de que en la practica, esa ayuda al desarrollo todavía 
no ha superado ni la mitad de esa cifra. En el caso de los Estados Unidos de Norteamérica, la ayuda al desarrollo es de apenas $0,1 \%$ del PIB, ocupando el último puesto en la lista de los países de la OCDE.

Así la renegociación de la deuda externa y por consiguiente, su extinción total, constituiría una importante vía para superar el atraso económico de eses países, porque a pesar de algunos países africanos ya tienen perdonados sus deudas, la necesidad del aporte complementar continua siendo el ponto de estrangulamiento de sus economías. No cabe duda que de cumplirse las estimaciones, el alivio de la deuda permitirá a estos países reorientar parte del gasto público a financiar proyectos de desarrollo. Solo así los respectivos gobiernos tendrán la posibilidad de concentrar en las políticas de reformas necesarias al desarrollo sostenible, encaminando recursos para sectores de salud, educación, saneamiento e infraestructuras básicas.

Urge, púes, el establecimiento de una Nueva Orden Económica Internacional, más democrática, más equitativa y equilibrada que reconcilie harmoniosamente los intereses del mundo industrializado y los dos países subdesarrollados así como reformular las relaciones financieras y económicas internacionales. Una vez, Edgard Luttak afirmó: A no ser que se haga frente de una recolonización que establece a las Naciones Unidas como administración a largo plazo de cada vez mayor números de colonias africanas, la única cosa que se podrá hacer es abandonar la suerte cada país y sus pueblos. El nivel del desarrollo político que en ellos prevalece es sencillamente insuficiente para poner en funcionamiento las estructuras del estado moderno. Inevitablemente sus líderes son los principales saqueadores de sus respectivos países, los burócratas actúan como chantajistas, los militares son generalmente la mayor amenaza a la seguridad pública, y los políticos son más propensos a robar a sus ciudadanos que defenderlos propiamente.

No hay que negar rotundamente la realidad de esta afirmación, pero en defensa de la democratización de la región empujada por factores endógenos, hay que reconocer que la realidad de ASS es muy compleja. Por eso en la actual coyuntura política que trajo una nueva realidad; la globalización; se debería hacer valer una nueva voluntad política que hiciera que los occidentales y los africanos se esforzaran de superar determinados comportamientos del pasado y favorecer las verdaderas posibilidades del desarrollo de ASS adaptado a su realidad y al servicio de sus necesidades. 
Las raíces históricas del atraso económico en África Subsahariana

\section{CONCLUSIONES}

unas personas son muy pobres, sin culpa alguna y otras son muy ricas y no por meritos propios

Paul Samuelson

Es de conocimiento general que existe una gran responsabilidad del occidente en el subdesarrollo africano. Pero lo más grave es que por detrás de todas las guerras civiles en África pos-independencia, están los países industrializados con motivo de vender sus arsenales bélicos y deshacerse de los stocks en los almacenes. Para muchos existe la gran pregunta si realmente existe la intención de acabar con la pobreza, el hambre y el subdesarrollo en ASS. Estas cuestiones merecen gran reflexión y que en última instancia quienes tienen que resolver esa problemática serán los propios africanos, porque están en una carretera de única vía, sin vuelta para tras ni para los lados, simplemente hay que seguir adelante y tentar alcanzar los objetivos deseados por toda su población que ya ha sufrido mucho. Los presidentes de los países de ASS donde es común la pobreza, ellos mismos son pobres no solo financieramente, pero también en términos de capacidad institucional.

Por lo visto, no existe un consenso doctrinal sobre las condiciones que hacen posible la democracia y su posterior consolidación en ASS. Algunos defienden la existencia de una conexión entre la democracia y el desarrollo económico, otros insisten en la necesaria existencia de valores y actitudes democráticos entre los ciudadanos, otros incluso defienden la importancia de la estructura política, la vitalidad de las instituciones, la influencia externa o la unidad nacional. Pero como siempre hay que tener algo como enganche, como base, por lo que se apunta colonización europea y en la división territorial de la conferencia de Berlín en 1885 como sus orígenes. Las divisiones artificiales del territorio reforzaron uno de los problemas más graves del continente, que a par de la complejidad étnica y de su falta de estructuración económica, constituyen formidables obstáculos al suceso de la democracia en la zona.

Otros factores merecen ser analizados como son, el confronto lesteoeste que hizo de África uno de sus palcos privilegiados, primando la segu- 
ridad sobre cualquier experiencias política que pudiera ser desestabilizadora; y por otro lado, las propias clases dirigentes africanas pos-coloniales que argumentaban con la necesidad del desarrollo económico para justificar gobiernos autoritarios más preocupados por el poder que el bienestar de sus ciudadanos. El ASS relegado a un tercer plano por las políticas de las grandes potencias, y también por la desastrosa actuación de varios de sus dirigentes, continúa su desfile de miseria e indigencia, observando como el más importante de su riqueza, el hombre, desaparecer en guerras muchas veces consideradas étnicas, que esconden a su verdadera esencia originaria en la lucha entre las grandes potencias económicas por una nueva distribución de los mercados, en esa rica zona del planeta.

\title{
HISTORICAL ROOTS OF THE ECONOMIC BACKWARDNESS IN SUB-SAHARAN AFRICA
}

\begin{abstract}
Currently, studies on economic development and poverty reduction in developing countries, and especially in Sub-Saharan Africa, have raised the attention of specialists from around the world who have investigated the theme under different theoretical perspectives. Despite multiples efforts, there has not been found an integrated development strategy for Sub-Saharan Africa, since the prevailing political ideologies are unable to disconnect from traditional production processes which are linked back to the colonial mode of production. To understand the situation in Sub-Saharan Africa, we need to irremediably be linked to its development process with former metropolises. In this context, the objective of this article is to present the origin and the causes of underdevelopment as well as the major initiatives made in the attempt to exit stagnation, in terms of a globalized conjuncture, which is entirely unfavorable for the countries in the region in question.
\end{abstract}

Keywords: Sub-Saharan Africa; underdevelopment; globalization 


\section{BIBLIOGRAFÍA}

AIF y FMI. Iniciativa para los países pobres muy endeudados. Estado de aplicación, DC/2001-0012. Washington: 2001.

AMIN, Samir. Miradas a un medio siglo. Itinerario Intelectual 1945-90. Lepala y Plural. La Paz: 1999.

AMIN, Samir; VERGOPOULOS, Kostas. A questão agrária e o capitalismo. Rio de Janeiro: Paz e Terra, 1977.

ANDREWS, D. et al. Alivio de la deuda para los países de bajo ingreso. Iniciativa reforzada para los países pobres muy endeudados. Fondo Monetario Internacional, nº51-S. Washington: 1990.

BARI, Mamadu Lamarana. África e desenvolvimento. Salvador: 2006. Disponível em: $<$ http://www.didinho.org/AFRICAEDESENVOLVIMENTO.htm>. Visto en: abr. 2008.

BID. Informe del progreso económico y social. Desencadenar el crédito. 2004

CEPAL. Panorama social de America Latina y el caribe. 2004

CEPAL. La CEPAL en sus 50 años. Notas de un seminario conmemorativo. Santiago de Chile: 2000.

CÉSPEDES, Gemma Cairó; JAÉN, Artur Colom. El alivio de la deuda en África. ¿Hacia la reducción de la pobreza?, ICE, tribuna de Economiza, Enero-Febrero 2003.

COLECTIVO DE ACTORES. Las Teorías Acerca del Subdesarrollo y el Desarrollo: una visión crítica. La Habana: Editorial Félix Varela, 2006.

DIALLO, Oumar Alfa, T. A Nova Parceria para o desenvolvimento da África (NEPAD) - Paradigma para o Desenvolvimento. Porto Alegre, 2006. 
FURTADO, Celso. Desenvolvimento e Subdesenvolvimento. Rio de Janeiro: Fundo de Cultura, 1961.

Instituto Internacional de Agricultura Tropical (IITA) - Ibadan. Nigeria 2004.

PNUD. Informe del Desarrollo Humano. Programa de Naciones Unidas para el Desarrollo. 2000.

UNCTAD. Trade and Developmend Report. Unites Nations Conferences on Trade and Development. Ginebra: 1998

UNESCO. Instituto de estadística - Compendio mundial de la educación, 2007. 